\title{
The Interrelation of Agronomic Character and Mineral Nutrition as a Basis for Mathematical Model of Grain Growing in West Siberia
}

\author{
Eremina Diana \\ Department of Mathematics and Informatics, \\ Federal State Budgetary Educational \\ Institution of Higher Education \\ «Northern Trans-Ural State Agricultural University» \\ Tyumen, Russia \\ soil-tyumen@yandex.ru
}

\author{
Otekina Natalya \\ Department of Mathematics and Informatics, \\ Federal State Budgetary Educational \\ Institution of Higher Education \\ «Northern Trans-Ural State Agricultural University» \\ Tyumen, Russia \\ soil-tyumen@yandex.ru
}

\author{
Kayugina Svetlana \\ Department of Mathematics and Informatics, \\ Federal State Budgetary Educational \\ Institution of Higher Education \\ «Northern Trans-Ural State Agricultural University» \\ Tyumen, Russia \\ soil-tyumen@yandex.ru
}

\begin{abstract}
Modern agriculture strongly relies on mineral fertilizers that make it possible to increase the arable land productivity fast and cost-effective. The traditional use of fixed doses of mineral fertilizers under a free market economy is ineffective, as it does not reflect the character of soil fertility. The article explores the causes of hereditary links between nutrient removal and harvest elements. To plan the activities of agricultural enterprises it is required to use mathematical models for calculating the doses of mineral fertilizers. As initial data, the authors used the results of long-term experiments conducted at the Department of Soil Science and Agrochemistry of the Northern Trans-Ural State Agricultural University. The scheme of the experiment included the application of mineral fertilizers to the planned yield in spring wheat $3.0 ; 4.0 ; 5.0$ and $6.0 \mathrm{t} / \mathrm{ha}$. Mineral fertilizers were applied taking into account soil fertility that was estimated annually. In experiments, the content of nutrients in straw and grain was determined annually; removals were calculated. The data obtained shaped the basis for the development of a mathematical model for spring wheat feeding. There was revealed: a high correlation between nutrients and biogenic removal; the ratio of grain to straw; yield of the byproducts at harvest. Regression equations can be used to calculate the doses of mineral fertilizers for the planned yield in grain crops. A high approximation coefficient confirms the reliability of the derived equations. A regression mathematical model of correlated indicators is presented. The indicators can be used to optimize the fertilizer system, to plan agricultural enterprises and in studies as well.
\end{abstract}

Keywords- mineral fertilizers, spring wheat, leached chernozem, mathematical model, approximation coefficient.

\section{INTRODUCTION}

Agriculture in West Siberia is one of the most complex economic systems in the Russian Federation. Expanded reproduction in the region is the relationship of biological, technological, organizational and economic processes. In West Siberia, this is achieved only through the development of science that provided agriculture with new varieties of crops, animal and bird species that can survive in extreme climatic conditions $[1,2,3]$.

Intensification of agriculture requires science to scientifically substantiate the use of mineral fertilizers for planned crop yields. In the past, this problem was solved by agrochemical research throughout the country and methodological recommendations for the cultivation of certain crops for a particular region. Such recommendations were used everywhere. They were enough for agronomists, as there were very few varieties, technologies were elaborated and unified for the country. At present, the situation is completely different new varieties of intensive crops emerge every year. The system of crop rotation and tillage is individual for each farm. New forms of fertilizers are produced $[4,5]$. In such conditions, the developed methodological recommendations for growing crops are becoming less relevant, and in some cases, even completely useless.

Old fertilizer systems with fixed doses for a specific crop and soil have been replaced with new technologies for calculating fertilizer doses on the basis of feeding mathematical models. They are not bound to specific varieties, soils and climatic conditions, although they are rather difficult to 
calculate. In this case, modern computer systems come to help due to their ability to store a relatively large database and calculate online the required doses of fertilizers that ensure the receipt of products with specified quality characteristics.

With no evidence-based production strategy it is almost impossible to solve the problem of obtaining stable and economically viable harvest. The most important element in the strategy is the use of such modern plant nutrition technologies as differentiated fertilization taking into account biological characteristics of grain, soil and weather conditions [6]. According to leading researchers, the removal of nutrients by spring wheat largely differs and depends not only on the variety itself but also on weather conditions in a certain period of plant development. Scientists from the State Agrarian University having spent many years of research proved that the use of plant food compounds differs notably between varieties of crops. Modern varieties, due to their genetic properties, are characterized by a different ability to absorb nutrients from the soil and use them, thereby affecting yields. Therefore, the system of fertilizers should be developed taking into account the biological characteristics of not only the cultivar but the variety as such. This will guarantee the variety to disclose its full biopotential.

Being rather complex and multifaceted these problems require a wide application of mathematical methods and modern computers. Modern economic and mathematical methods provide a quick search for optimal options in the planning and management of the national economy. Calculation of optimal arable productivity with regard to bioclimatic potential is one of the most justified and effective applications of economic and mathematical methods in agriculture. Currently, IT-technologies significantly reduce the time and costs for making calculations aimed at the planning of enterprises $[7,8]$. These technologies make it possible to develop not only plant nutrition models but also enable to create artificial soils and improve technologically-disturbed lands [9, 10]. The mineral nutrition models designed to take into account the soil-climatic features of the region and the properties of modern varieties are relevant in the transition to the system of precise farming and rational nature management.

\section{SUBJECTS AND METHODS}

To develop the mathematical model, the results of long-term studies of the Department of Soil Science and Agrochemistry of the Northern Trans-Ural State Agricultural University were used. The study area of the Chair of Soil Science and Agrochemistry is located on the Tobol-Pyshminsky interfluve between the eastern edge of the Trans-Ural Plateau and used to study the organomineral fertilizer system. The study area was established on the territory of the instructional farm of Tyumen State Agricultural Academy $1.5 \mathrm{~km}$ from the village of Uteshevo and $10 \mathrm{~km}$ from the study area No.1. The experiments started in 1995 and are still being conducted. During the years of research, the crop rotation and the tillage system have not changed. Experimental plots are fixed. The relief of the plot is a slightly wavy plain with bolsons. Soil-forming rocks are represented by carbonate cover loams. The experimental plot is a plain with a barely noticeable slope to the northeast. The soil in the experimental field is chernozem leached thin clayey loamy pulverescent on carbonate cover loam [11]. Regarding the content of fractions of the granulometric composition, the cover rocks of this region differ significantly from the loesslike rocks of the European part of Russia. They are characterized by a very low content of dust fraction - from 10 to $40 \%, 4-17 \%$ of which account for large dust $(0.05-0.01 \mathrm{~mm})$. In addition, these breeds, unlike European loesses, are about 1.5-2.0 times less carbonate and more sanded. Such soils are typical of the foreststeppe zone of the Trans-Urals and are widely used in agriculture [12].

The studies were carried out during a cereal fallow rotation (annual grasses - wheat - oats). The organomineral system of fertilizers was studied to obtain the planned yield in spring wheat and oats $3.0 ; 4.0 ; 5.0$ and 6.0 t/ha. Straw, crushed during grain harvesting, was used as organic fertilizers. Doses of mineral fertilizers were calculated annually by the method of elementary balance. The repetition in the experiment was 4fold. The plot arrangement was consistent. The record plot was $100 \mathrm{~m} 2(25 \times 4)$. The protective areas around the experiment were $8 \mathrm{~m}$. The system of basic and preseeding treatment was traditional for the northern forest-steppe, i.e. moldboard and not of uniform depth. To cultivate grains (spring wheat and oats) plowing was carried out to a depth of $20-22 \mathrm{~cm}$; to cultivate annual grasses (pea-oats mixture) $-28-30 \mathrm{~cm}$. For the years of research, the crop rotation and treatment system did not change. Statistical processing was carried out using the odn1 software developed at the Department of Mathematics and Informatics of the Northern Trans-Ural State Agricultural University.

\section{RESULTS}

Long-term studies have shown that the biomass output of wheat agrophytocenosis in chernozem soils of the Trans-Ural region is $4.86 \mathrm{t} / \mathrm{ha}$ (Fig. 1), 2.82 tons of which are accounted for by by-products ( $58 \%$ of biomass). The ratio between grain and straw is 1.38 units. This is typical of the varieties of Russian origin. The application of mineral fertilizers to the planned yield of $3.0 \mathrm{t} / \mathrm{ha}$ increases both the grain yield and the straw output. The ratio between commodity and by-products goes up slightly and reaches 1.41 units. For an agricultural entrepreneur this is not critical and may not be accounted when developing a model of mineral nutrition.

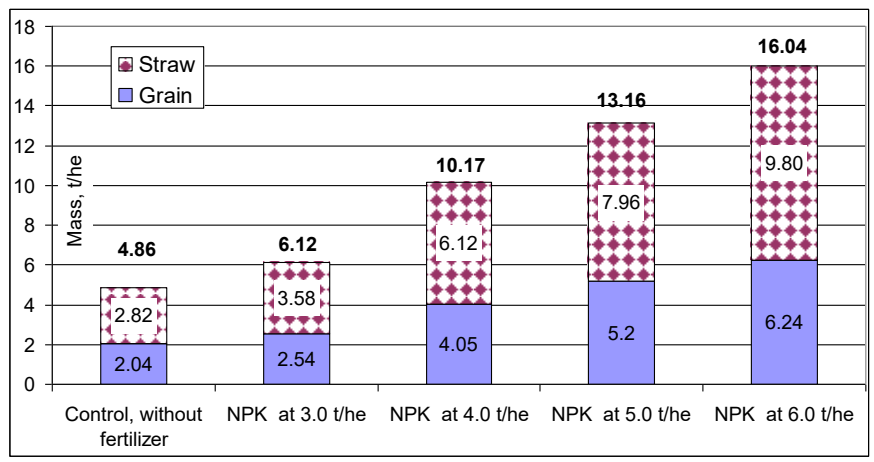

Fig. 1. Change in biomass of spring wheat when applying mineral fertilizers to the planned yield, $\mathrm{t} / \mathrm{he}$.

With the increase in the level of mineral nutrition of arable land, due to the application of mineral fertilizers, biomass 
increases substantially. For a planned yield of 5.0 and $6.0 \mathrm{t} / \mathrm{ha}$ of grain, it reaches 13.16 and 16.04 tons. It should be noted that in these cases the share of straw significantly increased with its mass accounting for more than $60 \%$ of the phytocenosis biomass. The ratio of grain weight to straw increased to 1.57 units. This fact indicates that the role of straw in the calculation of biogenic removal becomes rather important, particularly considering that with high soil fertility the straw accumulates an additional amount of nutrients. This must also be taken into account when developing plant nutrition models and fertility reproduction of agrozems.

The results of statistical analysis presented in Table 1 showed that the yield in spring wheat, as well as by-products, correlate with nutrients applied with fertilizers.

In the forest-steppe zone of the Trans-Ural region, the yield in spring wheat most strongly depends on the applied nitrogen and phosphorus with the correlation coefficient equal to 0.88 and 0.77 units, respectively. This fact is justified by the high content of these elements in the soils of the Tyumen region. Chernozems of the Trans-Ural forest-steppe zone are characterized by an unstable nitrogen status caused by the low microbiological activity. The reason for this is a short vegetation period and a great depth of freezing in winter, which entails an unfavorable temperature regime [13]. Therefore, for the formation of high crop yields, even on high-humus soils of the Trans-Urals, additional application of nitrogen fertilizers is required. However, a close relationship was established between the removal and release of by-products - it amounted to 0.80 units. This is justified by the fact that straw at the time of harvesting accumulates large amount of nitrogen in the form of various compounds. The reason for this is the physiological greenness of cereals with a shortage of heat at the end of summer. Since harvesting in the Trans-Urals is conducted under unfavorable weather conditions, the crops must be harvested in early September during the phase of wax ripeness, when nitrogen-containing substances cannot be transported from the vegetative part to the grain.

In general, all chernozems are characterized by relatively high potential of total phosphorus that is however quite low to be available to plants (mono- and diphosphates). The chernozem soils in the south of the Tyumen region in terms of phosphate content are classified as high-end agricultural land. The reason for this is their total and repeated phosphorylation in the 70 s of the last century. Therefore, crops grown in such fields do not lack phosphorus and can easily absorb it at different development stages. Climatic features of the region affect the phosphorous status of agricultural crops. The beginning of spring vegetation is marked by a very weak absorbing ability of soil phosphorus, since it depends on moisture and temperature conditions of the root zone. On average, over the years of research, the soil temperature in late May and early June at a depth of 15-30 cm did not exceed 10 degrees Celsius. Therefore, phosphorus absorption was possible only from the upper, already heated layer. On the other hand, in spring there are unfavorable moisture conditions, i.e. the soil dries to the degree of permanent wilting. Maximum absorption of phosphorus from the soil is noted only in the second half of June. In late summer, the crops can again intensively absorb phosphorus which they no longer need. The reason for this is the appearance of new stems resulting from secondary tillering. This is caused by high soil moisture in the second half of the vegetation period. Cereals during this period start to freely absorb phosphorus, since moisture conditions and the temperature of the soil are favorable for this. In the end, a high correlation between the yield in spring wheat and the removal of phosphorus can be seen.

The studies showed a weak correlation between productivity and potassium applied with fertilizers. The correlation coefficient did not exceed 0.43 units. Unlike nitrogen and phosphorus, potassium is easily absorbed by crops from the soil. The absorption process is not affected by the moisture conditions, temperature and acid-alkaline characteristics of soils.

TABLE 1 STATISTICS OF THE INTERRELATION BETWEEN THE NPK REMOVAL AND THE STRUCTURAL ELEMENTS OF SPRING WHEAT PRODUCTIVITY

\begin{tabular}{|c|c|c|}
\hline Indicators & $\begin{array}{c}\text { Correlation } \\
\text { coefficient }\end{array}$ & $\begin{array}{c}\text { significance } \\
\text { point }\end{array}$ \\
\hline \multicolumn{2}{|c|}{ Nitrogen } & \\
\hline Removal-crop yield & 0.88 & 0.001 \\
\hline Removal-straw yield & 0.72 & 0.010 \\
\hline Removal-ratio of straw to crop & 0.84 & 0.001 \\
\hline Phosphorus & \\
\hline Removal-crop yield & 0.77 & 0.010 \\
\hline Removal-straw yield & 0.42 & 0.010 \\
\hline Removal-ratio of straw to crop & 0.75 & 0.010 \\
\hline Potassium & 0.010 \\
\hline Removal-crop yield & 0.43 & 0.010 \\
\hline Removal-straw yield & 0.80 & 0.010 \\
\hline Removal-ratio of straw to crop & 0.84 & \\
\hline
\end{tabular}

The soils in the forest-steppe zone of the Trans-Urals are classified as highly potassium, so it is usually not necessary to apply potassium fertilizers to crops. Thanks to the very high reserves of gross potassium in the soil-forming rocks and the mineral part of soils, an agricultural entrepreneur working in the Trans-Urals for decades does not use potash fertilizers, and the arable land does not even show signs of a deficiency of this nutrition element.

The correlation between biogenic nitrogen removal and the ratio of spring wheat grain to straw is also very close -0.84 units, which enables to use this indicator to create a regression equation. This is also acceptable with respect to potassium. The connection between phosphorus and the ratio of spring wheat grain to straw remains strong but the correlation coefficient is less, with respect to nitrogen and potassium -0.75 units. However, it also shows that the resulting regression equation will be reliable.

The high reliability of the connection of the studied features undoubtedly indicates the possibility to use it for the development of regression equations describing this relationship in algebraic form. In this case, according to the regression equations, it is possible to predict statistically reliably the biogenic nutrient removal separately for each spring wheat productivity index, or to use the ratio of grain to straw. Despite the fact that the correlation coefficient in this case is high, it will be more interesting for the agricultural entrepreneur 
to set up a regression equation for biogenic nutrient removal, calculated by multiplying the planned yields by the removal. As shown by the research, this indicator for spring wheat varieties does not differ to a great extent. Since it is almost the same for all spring wheat varieties, by using the regression equations in simulation modeling one can estimate different needs for nutrients to form the planned yield. The removal corresponds to the amount of nutrients committed on the formation of a unit of basic production. On the basis of this information, the doses of mineral fertilizers can be determined by the formula (Dose $=$ planned yield * removal-the content of the nutrient in the soil).

Mathematical analysis enabled to derive regression equations for calculating the doses of mineral fertilizers $(1,2)$ :

Nitrogen - $Y=6.27 * X-4.45 * X_{1}-80.29$

Phosphorus $-Y=6.11 * X-12.75 * X_{1}-63.3$

where

$Y$ - doses of mineral fertilizers, $\mathrm{kg}$ r.a./ha;

$X$ - planned yield, dt/ha;

$X_{1}$ - content of nitrate nitrogen $(\mathrm{mg} / \mathrm{kg})$; phosphorus (mg/100 g).

Regression statistics showed that the correlation coefficient between the planned yield, nutrient content and the dose of mineral fertilizers is as follws: for nitrogen - 0.94; for phosphorus -0.93 . The approximation coefficient is 0.87 units, which indicates the reliability of the predicted results. The presented equations are valid only in the range of 1.5-6.0 t/ha. With an increase in the planned yield by more than $6.0 \mathrm{t} / \mathrm{ha}$, it is necessary to revise the current indicators and add some new such as reserves of productive moisture in the soil, the sum of effective temperatures, etc.

With this methodological approach, the biological characteristics of crops and varieties serve as arguments in mathematical models, which is regarded as a benefit for using the method. It is also important that the consumption of nutrients is considered as an effective feature. The correspondence between the argument and the function can be expressed by a table, a formula, a schedule, and this, in turn, allows for an extremely clear quantitative assessment of the consumption of elements of mineral nutrition by any agricultural crop.

Another significant advantage of the proposed method is that the consumption characteristics of mineral nutrition provide the opportunity to calculate the standards for nitrogen, phosphorus and potassium consumption for the formation of a production unit of different grain crops when cultivating them through various technologies and, accordingly, calculate the payback on mineral fertilizers with varieties of grains. Furthermore, it is clearly seen that there is real possibility of avoiding the use of various coefficients in calculations of fertilizer doses whose consistency has not been statistically proven yet (for example, the coefficients of nutrient utilization from soil, fertilizers, etc.).

\section{CONCLUSION}

The considered method of mathematical simulation to calculate doses of mineral fertilizers for the planned yield in spring wheat is an objective basis for the development of fertilization systems for new varieties cultivated under any system of agriculture with different intensification levels. The obtained data can become a basis for creating an optimization model for feeding crops. Developing appropriate models requires to provide for specific features of forming economicvaluable properties when introducing mineral fertilizers taking into account regional soil-climatic traits.

\section{References}

[1] A. Lyubimova and D. Eremin, "Laboratory varietal control as a guarantee of successful work of gribusiness in Russia," [MATEC Web of Conferences, $170, \quad 2018, \quad$ pp. https://doi.org/10.1051/matecconf/201817004015

[2] M.A. Chasovshchikova, O.M. Sheveleva, M.A. Svjazhenina, N.I. Tatarkina, A.V. Satkeeva, A.A. Bakharev, E.A. Ponomareva and A.G. Koshchaev, "Relationship between the genetic variants of kappa-casein and prolactin and the productive-biological characteristics of cows of the black-motley breed", Journal of Pharmaceutical Sciences and Research, 9, 2017, pp. 1038-1044.

[3] Y.P. Loginov, A.A. Kazak, L.I. Yakubyshina, T.N. Falaleeva, S.N. Yashchenko and E.T. Yarova, "Breeding value of collection varieties of potato in the forest-steppe zone of the Tyumen region", Journal of Pharmaceutical Sciences and Research, 1, 2018, pp. 377-380.

[4] D.T. Degefie, E. Fleischer, O. Klemm, A.V. Soromotin, O.V. Soromotina, A.V.Tolstikov and N.V. Abramov, "Climate extremes in south western Siberia: past and future" Stoch. Environ. Res. Risk Assess, 28 (2014), pp. 2161-2173. DOI: 10.1007/s00477-014-0872-9.

[5] I. Kuhling, D. Redozubov, G. Broll and D. Trautz, "Impact of tillage, seeding rate and seeding depth on soil moisture and dryland spring wheat yield in Western Siberia", Soil \& Tillage Research, 2017, 170, pp. 43-52. DOI: 10.1016/j.still.2017.02.009

[6] D.I. Eremin, "The use of modern data about the composition and properties of soil for the development of transport infrastructure of Tyumen" [IOP Conference Series: Earth and Environmental Science], 2017, vol. 90, Conf. 1. DOI: org/10.1088/1755-1315/90/1/012021.

[7] D. Eremina, "IT-technologies in soil Informatics and Russian agribusiness," [MATEC Web of Conferences, 170, 2018, pp. 04016]. DOI: https://doi.org/10.1051/matecconf/201817004016

[8] D. Eremina, "The impact of transport infrastructure on ecological status of arable land in Western Siberia”, [MATEC Web of Conferences. 170, 2018, pp. 05004]. https://doi.org/10.1051/matecconf/201817005004

[9] A.V. Iglovikov, "The development of artificial Phytocenosis in Environmental Construction in the far North", Procedia Engineering, 165, 2016, pp. 800-805. DOI:10.1016/j.proeng.2016.11.778.

[10] A.S. Motorin, A.V. Bukin and A.V. Iglovikov, "The water regime of the long-seasonally-frozen peat soils of the Northern Trans-Ural," [IOP Conference Series: Earth and Environmental Science 90, 2017] doi.org/10.1088/1755-1315/90/1/012053

[11] D.I. Eremin, "Changes in the content and quality of humus in leached chernozems of the Trans-Ural forest-steppe zone under the impact of their agricultural use", Eurasian soil science, 2016, 5, pp. 538-545. DOI: 10.1134/S1064229316050033

[12] D.I. Eremin and N. A. Gruzdeva, “ Influence of anthropogenic factor on microaggregate composition of gray forest soils", Siberian Bulletin of agricultural science, 1, 2018, pp. 28-37.

[13] D.I. Eremin, "Soils swelling as a regional feature of Western Siberia", [MATEC Web of Conferences, 170, 2018, pp. 02017]. https://doi.org/10.1051/matecconf/201817002017 